Revista Docência e Cibercutura

\title{
PAULO FREIRE NAS PRÁTICAS CIBEREDUCATICAS: NARRATIVAS DOCENTES DURANTE A PANDEMIA COVID 19
}

\author{
Edméa Santos ${ }^{1}$ e Lucila Pesce $^{2}$ (Organizadoras)
}

Estamos vivendo um dos mais difíceis momentos de nossas vidas. A pandemia Covid-19 matou e vem matando cotidianamente. No Brasil, até a publicação do presente dossiê, são mais de 600 mil mortes. Como se não bastasse, esta estatística se agrava a cada dia, pelo fato de estarmos vivendo uma tragédia política multidimensional. Negacionismo, práticas antidemocráticas, crimes contra direitos humanos, de racismo, de homo e transfobias, de machismo, apologia à ditatura e a torturadores, só para citar alguns dos muitos nefastos episódios da atual história política brasileira. Neste contexto, Paulo Freire, patrono da educação brasileira, vem sendo sistematicamente atacado, em função da sua luta histórica pela "educação como prática da liberdade". Não à toa, Freire foi exilado no contexto da ditadura militar, de 1964 a 1984. Pouco mais de trinta anos após, sua memória e obra voltam a ser desrespeitadas com discursos e práticas de ódio.

Por estes e outros motivos, nós, educadoras e educadores críticos e democráticos, estamos constantemente refutando as mazelas aqui citadas e anunciando atos de currículos e práticas pedagógicas democráticas e sintonizadas com a cultura do nosso tempo, cujas práticas sociais em grande medida se erguem em meio à cibercultura. A cibercultura é a cultura contemporânea que revoluciona a comunicação, a produção e a circulação em rede de informações e conhecimentos, na interface cidade-ciberespaço. Novos arranjos espaço-temporais emergem e, com eles, novas práticas de pesquisa e formação.

\footnotetext{
${ }^{1}$ Professora Titular-Livre da Universidade Federal Rural do Rio de Janeiro/Programa de Pós-Graduação em Educação e Programa de Pós-Graduação em Educação da UERJ. Sites institucionais: http://cursos.ufrrj.br/posgraduacao/ppgeduc/, www.proped.pro.br. Ambiente Virtual: www.docenciaonline.pro.br. Coordenadoras do GT 16 da Anped (2017-2019; 2019-2021)

2 Doutora em Educação (PUC-SP), com pós-doutorado em Filosofia e História da Educação (Unicamp); Professora Associada da Unifesp; membro do quadro permanente de professores do PPGE - Unifesp. Líder do grupo de Pesquisa LEC: Linguagem, Educação e Cibercultura. Coordenadoras do GT 16 da Anped (2017-2019; 2019-2021)
} 


\section{Revista Docência e Cibercultura}

Queremos com este dossiê, anunciar! Anunciar boas práticas, revisões conceituais, dispositivos de pesquisa e formação que articulam fundamentos e práticas ciberculturais, celebrando, resgatando e exultando a memória, o legado e obra de Paulo Freire. A Revista Docência e Cibercultura não poderia, também, deixar de celebrar o centenário de Paulo Freire. O patrono da educação brasileira vive em diferentes salas de aula e redes educativas, na relação cidade-ciberespaço. Seus conceitos, fundamentos, experiências e projetos vêm sendo atualizados por seres humanos, em processos de comunicação e educação mediados pelo digital em rede.

Neste número temático contamos com nove artigos científicos, uma performance visual e duas ações acadêmicas institucionais que homenagearam Paulo Freire, com lives, conferências, palestras, mesas redondas e conversas online. Intelectuais, educadoras e educadores, docentes, estudantes brasileiros e internacionais vêm atualizando a memória e a obra de Paulo Freire com dispositivos e interfaces digitais síncronas e assíncronas. O conjunto de lives, que poderão ser acessadas aqui, são dispositivos organizados pelas organizadoras desse número temático, que, juntamente com seus pares na UFRRJ (Universidade Federal Rural do Rio de Janeiro) e da UNIFESP (Universidade Federal do Estado de São Paulo), forjaram homenagens formativas em contexto de educação online e educação aberta. Isso significa, que podemos utilizar todo material presente aqui, para dispararmos outras e diferentes conversas, aulas e ambiências formativas.

$\mathrm{O}$ artigo que relata a performance visual, apresenta um diálogo subjetivo entre dois personagens emblemáticos na atualidade, com corpos em fricção: Paulo Freire e Marielle Franco, que teve como objetivo a produção artística e cultural através da performance audiovisual com um manifesto poético sobre os pensamentos do primeiro e a vida da segunda, a partir da "metodologia do encontro". O resultado deste trabalho foi a potência do encontro entre o simbólico de Marielle Franco e a perspectiva de Paulo Freire, nos demonstrando o quanto (sobre)viver é um ato político! Estes personagens deixaram suas vidas e obras como legado, ou melhor dizendo, sementes.

Contamos com o ensaio "Educar em tempos de pandemia: desafios da profissão docente", de autoria de Júnior Leandro Gonçalves e Lucila Pesce que traz explícito o objetivo principal: refletir sobre os diversos desafios que os docentes têm enfrentado neste 


\section{Revista Docência e Cibercultura}

momento de pandemia do COVID 19, com a imposição de diversas plataformas digitais, políticas públicas frágeis e a recorrente deslegitimação e desvalorização da profissão docente. Explana e elenca os problemas que se agudizaram diante do contexto pandêmico e como esses problemas reforçaram o descaso do poder público para com a educação pública, em especial para com os docentes. Com base na pedagogia e dialogia freiriana e os pressupostos da prática para a educação libertadora, considera-se que os problemas apresentados serão enfrentados se a profissão docente for considerada sob perspectiva colaborativa, autônoma e autoral, em face da realidade e dos contextos plurais nos quais as escolas estão inseridas. Vamos agora conhecer um pouco mais sobre o conjunto dos artigos aqui presentes.

Joselito Manoel de Jesus, Zuleide Paiva da Silva e Ana Lúcia Gomes da Silva, com o texto "Práxis na cibercultura: dialógica entre a pedagogia freiriana e as pedagogias feministas", tem como objetivo abordar as interrelações entre a pedagogia freiriana e as pedagogias feministas no contexto da cibercultura e as potencialidades para a compreensão e promoção das práxis produzidas pelas pedagogias feministas em suas intervenções emancipatórias. De natureza investigativa, assume pesquisa bibliográfica e documental como procedimentos metodológicos, tomando a práxis na cibercultura com ênfase nas pedagogias apresentadas na docência online, sustentadas em posições políticoepistemológicas comuns, que valorizam as curiosidades e produções socioculturais das mulheres e dos homens em seus vínculos socioafetivos e em seus compromissos políticos. Adotou-se, como corpus de análise o conjunto de narrativas, produções imagéticas, fotografias, que se constituíram como produção da experiência gestada coletivamente nos componentes curriculares Estágio Supervisionado II, da graduação em Letras e Pesquisa Aplicada à Educação II, na Pós-Graduação em Educação. Os resultados apontam evidências de aprendizagens, e indícios que de criação, a coautoria e cocriação, quando tanto os princípios epistemológicos e organizativos da metodologia, quanto do desenho didático propiciam aos estudantes e docentes, ambiência favorável e desafiadora, tais como: imersão em ambiências híbridas. Apontaram ainda os alinhamentos e inflexões realizadas no processo, realizando escuta sensível coletivamente com os sujeitos envolvidos. Os saberes fazeres emergentes da experiência apontaram também que a 


\section{Revista Docência e Cibercultura}

pandemia suscitou em todos e todas nós educadores e educadoras, novas formas de encontro com os nossos estudantes, em que o acolhimento, a produção das subjetividades, o lugar de escuta se fizeram ainda mais imprescindíveis a uma humana docência mediada pelas tecnologias digitais.

Com o artigo "Autonomia, colaboração, autoria e docência na cibercultura Questões sob a ótica de Freire e Bernstein”, Clarisse de Mendonça e Almeida, Vittorio Leandro Oliveira Lo Bianco, articularam as obras de Freire (1996) e Bernstein (2000) para abordar os conceitos de autonomia, colaboração e autoria compreendendo-os como elementos fundamentais da cibercultura (SANTOS, 2019) para pensar caminhos para uma educação mais flexível e focada não apenas na atuação docente, mas também na participação do aluno. Para tanto, parte-se do debate sobre a formação continuada docente como questão central para o desenvolvimento de um profissional capaz de, criticamente, compreender e atuar frente aos desafios impostos pela cibercultura (SANTOS, 2019) no que se refere à autoria e à colaboração na produção do conhecimento. Em seguida, propõe-se a articular este pensar com a estruturação de processos de ensino menos estruturados na figura central do professor e mais na autonomia do docente (FREIRE, 1990) e na contribuição de todos os envolvidos como elemento de ruptura aos modelos hierárquicos de educação (BERSTEIN, 1990). Para tanto, pretende-se gerar a compreensão de que tais objetivos somente se alcançam ao construirmos a figura do docente como um ser investigativo (NÓVOA, 2017), dotado naturalmente de curiosidade epistemológica (FREIRE, 1990).

Marilda Aparecida Behrens, Patricia Lupion Torres e Edna Liz Prigol, com o artigo "Revisitando os construtos de Paulo Freire para o enfrentamento da docência na crise causada pela pandemia”, destacam a diversidade de realidades no processo educativo nacional e internacional e os desafios emergentes provenientes da pandemia de Covid-19 impactaram a atuação docente, que necessitou transpor a atuação presencial para a modalidade remota, mediada pelas tecnologias digitais. Frente a esse desafio, elegeu-se como questão de investigação: a experiência de alunos de um programa de pósgraduação stricto sensu mediado por tecnologias digitais, impostas pela pandemia de Covid-19, possibilita identificar os construtos freirianos como ponto de reflexão para a 


\section{Revista Docência e Cibercultura}

reestruturação da prática pedagógica? Objetivamente, buscou-se identificar, nos relatos dos alunos de um programa de pós-graduação stricto sensu que vivenciaram um processo educativo mediado pelas tecnologias digitais, em decorrência da referida pandemia, os construtos freirianos como base epistemológica para refletir sobre a prática pedagógica. A pesquisa, de abordagem qualitativa, configurou-se como um estudo de caso único. Para a construção dos dados, utilizou-se um questionário semiestruturado com questões abertas, aplicado a um grupo de mestrandos e doutorandos de um programa de pósgraduação stricto sensu de uma universidade privada de grande porte do Sul do país. A fundamentação epistemológica teórico-conceitual tem como principal autor Freire (1992, 1993a, 1993b, 1996). A investigação permitiu perceber que as contribuições dos participantes acolhem construtos da educação transformadora, apontada nas categorias: visão da aceitação do novo, afetividade, engajamento didático e interação e colaboração. A pesquisa reflete a necessidade de humanização, assim como de um pensamento ético e político, pautada num processo educativo baseado na dialogicidade e na amorosidade, que fundamentam a educação para a liberdade.

Com o artigo "Grupo de estudo: um relato de experiência sobre a mediação virtual durante a pandemia do Covid-19”, Geovânia de Souza Andrade Maciel apresenta um relato de experiência acerca de uma das atividades realizadas por meio do Projeto de Mediação Virtual. Trata-se de um grupo de estudo virtual realizado com alunos dos segundos anos de uma instituição de ensino de Ji-Paraná e de outra instituição pública de ensino situada na cidade vizinha, Ouro Preto do Oeste. O projeto teve como objetivo promover o aprofundamento do processo de aprendizagem por intermédio do ensino remoto, em decorrência da Pandemia de COVID-19. Como aporte teórico a criação do grupo pauta-se nos estudos de Freire (1996), Dayrell (2007) e em especial, na abordagem dos pesquisadores Murphy e Lick (2005). Isto posto, a atividade em pauta realizou-se por meio de um grupo no WhatsApp, onde os 57 participantes formaram uma comunidade com ênfase na troca de conhecimentos. Os resultados do grupo de estudo mostraram que a dinamização do ensino é fundamental para motivar o processo educacional e promover uma aprendizagem colaborativa. 


\section{Revista Docência e Cibercultura}

Jéssica Bittencourt França e Rodrigo Pedro Casteleira com o artigo "Pessoa surda e autonomia freireana: o ciberespaço como meio de soerguimento", destaca algumas possibilidades para a interação, autonomia e disseminação da Língua Brasileira de Sinais (LIBRAS) da comunidade surda tendo como intermédio os ciberespaços ou a geografia virtual. Estes entendidos como os meios de acesso às redes de internet que facilitam essa interação com um universo sócio-virtual, sem enfatizar a surdez. O livre acesso às redes possibilita aos surdos a possibilidade de comunicação, expressão, retenção de informações, aprendizagem e contato com o mundo externo sem precisar necessariamente do auxílio de uma terceira pessoa ouvinte nesse processo, o que permite maior privacidade e mesmo a autonomia. A autonomia refere-se ao conceito freirenano, por entendermos que ele pode ser um marcador pontual para pensar uma educação não inclusiva, mas mais democrática e de posicionamento de práticas educativas como prática de liberdade.

Com o artigo "Práticas docentes na cibercultura e o esperançar de professoras na pandemia: possibilidades educativas para tornar o inédito, viável” as autoras Ana Clara São Thiago, Karolyne Neves da Silva e Luciana Velloso, apresentam experiências formacionais e pedagógicas de professoras-pesquisadoras na pandemia que, apesar de suas diferentes atuações, encontram-se no desenvolver de suas pesquisas dentro cenário da pandemia da COVID-19, buscando criar 'sentidossignificações' outros com seus 'praticantespensantes' nesse processo. Vivendo em uma cultura contemporânea mediada pelas tecnologias digitais em rede - a cibercultura - e sua relação com a cidade e o ciberespaço, compreendemos a importância das práticas educativas no contexto de uma educação online e nas implicações que nos movem e se movem durante as práticas de 'aprendizagemensino' e as experiências vividas dentro das instituições de ensino. Entendendo as contribuições de Paulo Freire, no que tange ao 'inédito viável' e as rupturas com uma educação bancária, para dar espaço a uma educação libertadora, trazemos nossas práticas com alunos de graduação do curso de Pedagogia da UERJ e alunos do Ensino Fundamental I de uma escola pública localizada no Complexo da Maré - RJ, entrelaçando nossas pesquisas no sentido de nos movimentarmos em direção a uma 


\section{Revista Docência e Cibercultura}

maneira de 'fazerpensar' nossas práticas educativas de forma humanizada, sensível, empática e distante da dicotomia aluno-professor.

Aristóteles de Paula Berino e Talita Cabral da Ponte Carvalho, com seu artigo "Cartas sobre a discência e a docência on-line: uma experiência com Paulo Freire", discutem uma experiência docente na cibercultura, que foi realizado em sua instituição logo nos primeiros meses da pandemia. A forma de Cartas foi escolhida como uma prática do diálogo entre o docente do curso e uma discente para discutir o que significou, naquele instante, a impossibilidade do ensino presencial e a adoção da prática on-line, observando suas possibilidades, mas também seus impasses. Paulo Freire foi o autor estudado no curso abordando no artigo como ele foi também um personagem das nossas práticas nos encontros on-line, extraindo da leitura de algumas das suas obras concepções e valores sobre a educação que orientaram a razão para estudar quando a pandemia já traumatizava e precisávamos sustentar eticamente nossa escolha pela formação em tempos de emergência epidemiológica, inclusive. No artigo, a experiência do curso é recordada e refletida, passado um ano do início da sua realização, com destaque para as concepções de esperança e risco, como importante legado de Paulo Freire, que nos serve agora, na pandemia.

Jilvania Lima dos Santos Bazzo no artigo "Contribuições de Paulo Freire para o ensino da leitura e escrita: dimensão linguística", busca refletir sobre o pensamento freireano em relação ao ensino de leitura e escrita no contexto da cibercultura, destacando a sua dimensão linguística. Entende-se que, para o seu desenvolvimento teórico e metodológico, faz-se premente articular de modo indissociável a tríade: sujeitos, conhecimento e projeto social emancipatório para a formação humana. Por que a palavra se constitui substância e verbo para ensinar e aprender a ler e a escrever? E por quais razões a pesquisação do universo de fala inaugura esse processo? Por que as atividades de ensino exigem a leitura da realidade e a leitura da palavra escrita (re)produzidas em situações e contextos sociais concretos? Como as palavras se tornam a menor unidade da pesquisa e suas pautas sonoras compõem as unidades mínimas do pensamento filosófico de Paulo Freire? Quais são efetivamente os princípios linguísticos que fundamentam sua epistemologia educacional? A expectativa é que as discussões apresentadas possam 


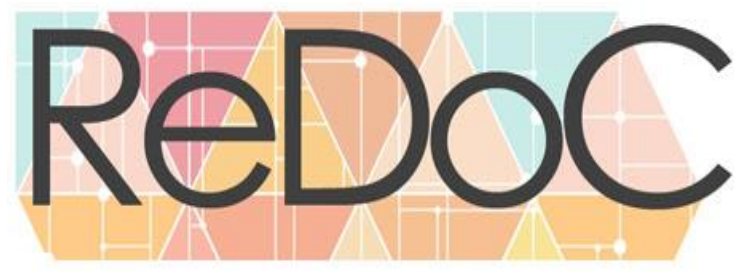

Revista Docência e Cibercultura

contribuir ainda mais para o fortalecimento dos atos pedagógicos emancipatórios e das pesquisas no campo da formação de professores, da alfabetização, da Didática e da educação em geral.

Paulo Freire vive! Inspira boas práticas, atos de currículos e bons sentimentos. Que sua memória e obra não sejam apenas lembrados neste ano de 2021, por conta do seu centenário de aniversário. Que sejam atualizados sempre por todos nós em nossas ação e projetos éticos, estéticos e políticas. Que cada sala de aula física ou online possa ser ambiência formativa, bem como as mais diferentes e plurais redes educativas e espaços multirreferenciais de aprendizagens. Que este número temático seja semente!

\section{REFERÊNCIAS}

ALMEIDA, Clarisse de Mendonça; LO BIANCO, Vittorio Leandro Oliveira. Autonomia, colaboração, autoria e docência na cibercultura - Questões sob a ótica de Freire e Bernstein. Revista Docência e Cibercultura, v. 5, n. 3, set.-dez., 2021, p. 84-103. DOI: https://doi.org/10.12957/redoc.2021.60097

BAZZO, Jilvania Lima dos Santos. Contribuições de Paulo Freire para o ensino da leitura e escrita: dimensão linguística. Revista Docência e Cibercultura, v. 5, n. 3, set.-dez., 2021, p. 191-206. DOI: https://doi.org/10.12957/redoc.2021.60147

BEHRENS, Marilda Aparecida; TORRES, Patricia Lupion; PRIGOL, Edna Liz. Revisitando os construtos de Paulo Freire para o enfrentamento da docência na crise causada pela pandemia. Revista Docência e Cibercultura, v. 5, n. 3, set.-dez., 2021, p. 104-122. DOI: https://doi.org/10.12957/redoc.2021.60106

BERINO, Aristóteles de Paula; CARVALHO, Talita Cabral da Ponte. Cartas sobre a discência e a docência on-line: uma experiência com Paulo Freire. Revista Docência e $\begin{array}{lllllll}\text { Cibercultura, } & \text { v. } 5, \quad \text { n. 3, set.-dez., 2021, p. 175-190. DOI: }\end{array}$ https://doi.org/10.12957/redoc.2021.60136

FRANÇA, Jéssica Bittencourt; CASTELEIRA, Rodrigo Pedro. Pessoa surda e autonomia freireana: o ciberespaço como meio de soerguimento. Revista Docência e Cibercultura, v. 5, n. 3, set.-dez., 2021, p. 139-150. DOI: https://doi.org/10.12957/redoc.2021.60056

GONÇALVES Júnior Leandro; e PESCE, Lucila. Educar em tempos de pandemia: desafios da profissão docente. Revista Docência e Cibercultura, v. 5, n. 3, set.-dez., 2021, p. 40-52. DOI: https://doi.org/10.12957/redoc.2021.61398 


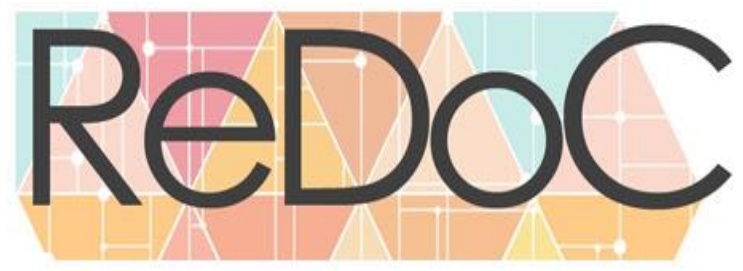

Revista Docência e Cibercultura

JESUS, Joselito Manoel de; SILVA, Ana Lúcia Gomes da; SILVA, Zuleide Paiva da. Práxis na cibercultura: dialógica entre a pedagogia freiriana e as pedagogias feministas. Revista Docência e Cibercultura, v. 5, n. 3, set.-dez., 2021, p. 53-83. DOI: https://doi.org/10.12957/redoc.2021.60085

MACIEL, Geovânia de Souza Andrade. Grupo de estudo: um relato de experiência sobre a mediação virtual durante a pandemia do Covid-19. Revista Docência e Cibercultura, v. 5, n. 3, set.-dez., 2021, p. 123-138. DOI: https://doi.org/10.12957/redoc.2021.60080

NASCIMENTO, Laurinaldo Félix; WUNSCH, Luana Priscila; FERNANDES, Maria Aparecida; LEAL, Maria Batista. A empatia freireana na alfabetização popular: concepções da cibercultura em tempos de pandemia. Revista Docência e Cibercultura, v. 5, n. 3, set.-dez., 2021, p. 207-221. DOI: https://doi.org/10.12957/redoc.2021.61235

OLIVEIRA, Danielle do Nascimento; SILVA, Bianca de Menezes Castro da. Dialogando com Paulo Freire e Marielle Franco: um manifesto poético através de uma performance audiovisual. Revista Docência e Cibercultura, v. 5, n. 3, set.-dez., 2021, p. 31-39. DOI: https://doi.org/10.12957/redoc.2021.61587

PESCE, Lucila Maria; HARDAGH, Claudia Coelho; GAMEZ, Luciano; LIMA, Valéria Sperduti; BATISTA, Sylvia Helena S da Silva; OLIVEIRA, Rosângela Aparecida Dantas de; GRACIANO, Mariângela. \#PauloFreire100Anos - transformação social e cultura digital: Memórias freirianas nas ações da UNIFESP - UAB. Revista Docência e Cibercultura, v. 5, n. 3, set.-dez., 2021, p. 27-30. DOI: https://doi.org/10.12957/redoc.2021.62855

SÃO THIAGO, Ana Clara; SILVA, Karolyne Neves da; VELLOSO, Luciana. Práticas docentes na cibercultura e o esperançar de professoras na pandemia: possibilidades educativas para tornar o inédito, viável. Revista Docência e Cibercultura, v. 5, n. 3, set.dez., 2021, p. 151-174. DOI: https://doi.org/10.12957/redoc.2021.60120

SILVA, Nathalia de Souza; SANTOS, Edméa Oliveira dos; MALACHIAS, Rosângela. Conversando com Paulo Freire - Diálogos dentro e fora do PPGEDUC/UFRRJ. Revista Docência e Cibercultura, v. 5, n. 3, set.-dez., 2021, p. 21-26. DOI: https://doi.org/10.12957/redoc.2021.62823

Este é um artigo de acesso aberto distribuído sob os termos da Licença Creative Commons Atribuição Não Comercial-Compartilha Igual (CC BY-NC- 4.0), que permite uso, distribuição e reprodução para fins não comerciais, com a citação dos autores e da fonte original e sob a mesma licença. 